Research Article

\section{An evaluation of visual outcome of corneal injuries in a tertiary care hospital}

\author{
Aarudhra Premchander ${ }^{1}$, Seema Channabasappa ${ }^{2}$, Nischala \\ Balakrishna ${ }^{3 *}$ and Neha Nargis ${ }^{4}$ \\ ${ }^{1}$ Resident, MBBS, India \\ ${ }^{2}$ Professor, Ophthalmology, MS, India \\ ${ }^{3}$ Junior Resident, MBBS, Bangalore, Karnataka, India \\ ${ }^{4} J u n i o r$ Resident, MBBS, Department of Ophthalmology, Vydehi Institute of Medical Sciences and \\ Research Centre, Bangalore, India
}

\section{Abstract}

Background: Corneal injuries are significant contributors to blindness. Cornea being the most anterior structure of eye is exposed to various hazards like airborne debris and blunt trauma. By understanding different types of injuries to which cornea is exposed, the practitioner maybe more capable in managing injuries to minimise structural and visual sequelae.

Objectives: To study various patterns of corneal injuries and its visual outcome among patients of ocular trauma in a tertiary care hospital.

Methods: Study of 100 cases of corneal injuries wherein patients were treated according to injury type and followed up for 4 months. Results: Majority of patients belonged to working population between age groups 21-65 years. Most patients suffered from corneal abrasions while the least common were perforating and lacerating injuries. Alkali injuries were more common than acid injuries. Most patient presented within 24 hours and had only epithelial defects. Therefore, the number of patients receiving conservative management was higher than those receiving surgical intervention.

Conclusion: Most common causes of blindness and low vision in our study was full thickness corneal laceration and corneal abrasions, foreign body injuries affecting the pupillary area and involving anterior or mid stroma causing nebular or macular grade opacities hampering vision.

\section{More Information}

*Address for Correspondence: Nischala Balakrishna, MBBS, Jr Resident, No 96, First Main Road Seshadripuram, Next to Sri Chaitanya Techno School, Bangalore, Karnataka, India, 560020, Tel: 91 8762558431/91 8217352997; Email: nischalabalakrishna@gmail.com

Submitted: 26 August 2019

Approved: 06 September 2019

Published: 09 September 2019

How to cite this article: Premchander A, Channabasappa S, Balakrishna N, Nargis N. An evaluation of visual outcome of corneal injuries in a tertiary care hospital. Int J Clin Exp Ophthalmol. 2019; 3: 020-029.

DOI: dx.doi.org/10.29328/journal.ijceo.1001022

Copyright: (c) 2019 Premchander A, et al. This is an open access article distributed under the Creative Commons Attribution License, which permits unrestricted use, distribution, and reproduction in any medium, provided the original work is properly cited.

Keywords: Corneal injuries; Corneal defect; Visual outcome; Epithelial defects; Corneal abrasion

Check for updates

\section{Introduction}

The cornea, as the most anterior structure of the eye, is exposed to various hazards ranging from airborne debris to blunt trauma of sufficient force to disrupt the globe itself. As a result, corneal injury may assume multiple forms and clinical presentations. Because the cornea is also the major refracting surface of the eye, minor changes in its contour result in significant visual problems [1]. Blindness is a major public health problem in most developing countries. Corneal opacification, as a cause of blindness, is second only to cataract in magnitude [2]. One of the most important preventable and avoidable causes of corneal blindness is corneal injuries. By understanding the different types of injuries to which the cornea is exposed, the practitioner may more capably manage these injuries and minimise the structural and visual sequelae of corneal injury. Ocular trauma and corneal ulceration are serious public health problems that are occurring in epidemic proportions [3]. Corneal opacification often leads to unilateral blindness, as exemplified by trauma, which is the leading cause of unilateral blindness in the world with a prevalence of $2 \%$ [4]. The most frequent causes of corneal blindness in at least one eye included keratitis during childhood (36.7\%), trauma $(28.6 \%)$, and keratitis during adulthood (17.7\%). Nearly $95 \%$ of all corneal blindness was avoidable [5]. Corneal and corneoscleral perforation and subsequent scarring due to ocular trauma may result in a variable amount of blindness [6]. Corneal abrasions (removal of part or all of the corneal epithelium) are one of the most common ophthalmic injuries [7].Second to corneal abrasions, corneal foreign bodies are the 
most common form of ophthalmic trauma [8]. In urban areas and the industrialized world, chemical injuries, accidents at the workplace, and automobile injuries are common. In rural areas of developing countries, minor trauma due to hazardous practices in agriculture, cottage industries, and other work places, as well as sports accidents, are responsible for a large proportion of corneal blindness. In addition, use of hazardous objects such as bows and arrows and lack of implementation of industrial safety regulations increase corneal morbidity from trauma [4]. It appears that early treatment can restore good vision and use of eye protective glass while working will be the preventable measure, and use of antibiotics drops after injury will be the proper method of treatment [9]. Diligence in diagnosis, patience and perseverance with regard to treatment goes a long way to alleviate the ocular morbidity. Hence this study is an attempt to study the clinical patterns, diagnosis, management and visual outcome of corneal injuries and also to educate the patient for better follow up during the course of treatment.

\section{Methodology}

\section{Source of data}

The materials for the study were drawn from corneal injury patients attending the Outpatient Department of Ophthalmology at Vydehi Institute of Medical Sciences and Research Centre, Bangalore from December 2017 to November 2018 and 100 patients of corneal injuries were recruited for the study and their follow up was done for a period of 4 months.

\section{Method of collection}

From the previous records analysed at our hospital, approximately 100 cases of corneal injuries were recorded in the previous year records. Assuming this reference a minimum of 100 cases attending the outpatient department of Ophthalmology from December 2017 to November 2018 were selected for the study and their follow up was done for a period of 4 months.

\section{Inclusion criteria}

- Patients presenting with ocular history of corneal injury due to trauma

- Patients of all age groups and either sex.

- Patients evaluated immediately after corneal injury.

\section{Exclusion criteria}

- Patients who did not give consent for the study.

- Ocular trauma cases where cornea is uninvolved.

- Poor patient compliance not willing to come for follow up.

- Patient with blind eye.
- Patients who are not available for follow up for a required period of time.

- Patients with history of previous corneal surgeries.

- Patients with head injuries in coma.

- Surgically induced corneal injuries

\section{Methodology}

Each patient was subjected to a detailed history taking followed by detailed ocular examination as per the enclosed proforma. Patients were advised to get admitted to the hospital for observation and better follow up. If not, they were advised to attend follow up in OPD without fail.

1) A detailed history and the aetiology of the injury were noted. Recording of visual acuity using Snellen's chart for the patients of ocular trauma was done.

2) Examination of anterior segment was done in detail with special emphasis on corneal involvement with the help of a slit lamp biomicroscope after instilling topical anaesthetising drop proparacaine $0.5 \%$ and the pattern of corneal injury were noted in detail and the management was according to the type of injuries.

3) Fluorescein staining was done to note the layers of the cornea involved in the injury.

4) Fundus examination

5) Lacrimal sac syringing

6) Routine laboratory investigations:

a) Complete hemogram

b) Random Blood Sugar

c) Urine- sugar, microscopy and albumin

d) HIV, HBsAg

7) Microbiological investigations as and when required were done as follows:

The sample for microbiological investigations was obtained by corneal scrapping. The cornea was anaesthetised using $0.5 \%$ proparacaine solution and scrapping was done using sterile No. 15 Bard Parker blade from the margins of the corneal ulcer.

The following microbiological investigations were done immediately:

a) Gram's stain

b) $10 \% \mathrm{KOH}$ preparation

c) Bacterial culture using blood agar and chocolate 
agar. Sensitivity was done using disc diffusion method if organisms were isolated.

d) Fungal culture was done using Saboraud's dextrose agar medium. Culture reports were declared negative at the end of 14 days.

8) Management of the patients proceeded on urgent basis and broadly classified as

\section{1) Corneal Abrasions}

- The eye was patched after instilling topical lubricating eye drops, topical antibiotic eye drops (Moxifloxacin 0.5\%), topical cycloplegic eye drops $(0.5 \%$ cyclopentolate or $2 \%$ homatropine), lubricating and antibiotic(moxifloxacin) eye ointment.

- The eye patch was removed after 24 hours to see for the healing. If not healed patching was continued every day for the next 2-3 days until the cornea was fluorescein staining negative.

- After removal of patch antibiotic, lubricating and cycloplegic eye drops were continued for another 3 days or as required depending upon the injury.

- Oral analgesics were given to reduce pain.

- If corneal ulcer developed it was managed as infective keratitis.

\section{2) Corneal Foreign body}

- Smaller objects were removed simply with a direct stream of sterile irrigating solution.

- More tenaciously stuck corneal foreign body was removed using a moistened cotton-tipped applicator.

- More deeply embedded objects were removed with a 26-gauge bent needle tip under the application of topical proparacaine $0.5 \%$ eye drops.

- Elimination of any remaining cellular debris or rust, as well as any ragged or non-viable epithelial tissue surrounding the wound was done.

- If perforation was suspected by performing Seidel's test then treatment for corneal perforation was performed.

- Eyelids and adnexa were carefully examined to see for any other foreign body and removed.

- Subsequent management and follow up after removal of foreign body was same as corneal abrasion above.

- X-ray or B scan was done to eliminate intraocular foreign body.

- Oral analgesics were given to reduce pain.

\section{3) Blunt trauma}

- If no corneal abrasions were found then other layers of cornea were inspected.

- In case of DM detachment conservative treatment with antibiotics and lubricating eye drops were used and if striae or any signs of raised intra ocular pressure were noted then topical antiglaucoma medications like timolol maleate eye drops $0.5 \%$ and acetazolamide 250 $\mathrm{mg}$ tab were given with usage of topical cycloplegics.

\section{4) Chemical injury}

Irrespective of the nature of the chemical involved in the injury the following treatment was given to the patients on an emergency basis:

- Critical step in the assessment is thorough examination of ocular surface for the presence of any particulate chemical matter by double eversion of the upper eyelid using an eyelid retractor.

- Copious irrigation of the eyes, preferably with saline or Ringer's lactate solution, for at least 30 minutes was performed. An eyelid speculum was inserted along with topical anesthetic before the irrigation.

- The lower eyelid was pulled down and the upper eyelid was everted to irrigate the fornices.

- Five to ten minutes after ceasing irrigation, litmus paper was touched to the inferior cul-de-sac. Irrigation was continued until neutral pH was reached (i.e., 7.0).

- Any loose bits such as lime was removed from the conjunctival sac and the conjunctival fornices were swept with moistened cotton tipped applicator to prevent formation of symblepharon.

- Necrotic tissue was removed to prevent epithelial healing and tonometry was performed.

- Topical antibiotics (moxifloxacin $0.5 \%$ or tobramycin $1 \% 4$ to 6 times/day) was started to prevent infection.

- Oral NSAIDs (Tab. Ibuprofen $400 \mathrm{mg}$, bid) along with topical cycloplegics (homatropine $2.0 \%$, bid) for pain relief.

- Anti-glaucoma medication (systemic or topical, according to the recorded IOP) Topical agents such as beta-blockers (timolol $0.5 \%$, bid) or oral agent, such as Acetazolamide $250 \mathrm{mg}$ bid-qid was used, titrated according to IOP.

- Topical corticosteroids were started in case of alkaline burns for the first 7-10 days, but was tapered quickly (within 2-3 weeks) either low dose like fluromethalone $0.1 \%$ or loteprednol $0.5 \%$ and high dose prednisolone $1 \%$ on case to case basis. 
- Additional topical agents that were employed include $10 \%$ sodium citrate and ascorbate, to decrease the incidence of corneal ulceration and perforation; Oral ascorbic acid (tab. Vit-C, 500mg qid) and oral doxycycline (100mg bid) to promote wound healing and prevent stromal ulceration.

- Topical tear substitutes both eye drops were used one hourly and eye ointment bid.

- On subsequent visits glass rod rotation with antibiotic eye ointment was performed each time to prevent symblepharon formation.

After noting down the aetiology of the chemical whether acid or base the following classification - (Table 1) was followed to determine the grade and prognosis.

This classification scheme for acid injury represents a modification of the one used for alkali injuries and represents a further adaptation of the system first proposed by Hughes.

This classification of alkali injuries was described by Hughes and modified by Pfister and Koski, (Table 2).

\section{5) Radiation injuries}

- Patient was started on hourly treatment with topical tear substitutes eye drops, tear substitute eye ointment bid, topical cycloplegic ( $2 \%$ homatropine) bid, topical antibiotics if required, topical NSAIDS eye drops (flurbiprofen $0.3 \%$ or ketorolac $0.5 \%$ ) 4 times a day and oral analgesics.

\section{6) Thermal injuries}

- Patients were treated same like corneal abrasion injuries with eye patching and use of topical antibiotics, cycloplegics, tear substitutes and oral analgesics.

- Anti-glaucoma eye drops and topical NSAID eye drops were given on case to case basis.

\section{7) Bee sting injuries}

- Individual stings were taken out using epilation forceps from the anterior segment. Careful inspection was done under full light intensity and magnification to not leave behind any more stings.

- Topical antibiotics and tear substitutes were started hourly with cycloplegic eyedrops bid.

- Tonometry was performed and anti-glaucoma medication topically timolol maleate $2 \%$ was initiated.

Table 1: Classification and prognosis in acid injuries of the eye [22].

\begin{tabular}{|c|c|c|c|c|c|c|}
\hline Grade & Epithelial opacity, defect & $\begin{array}{l}\text { Stromal oedema, } \\
\text { opacity }\end{array}$ & Conjunctival involvement & $\begin{array}{l}\text { Limbal ischemia } \\
\text { (whitening) }\end{array}$ & Recovery & $\begin{array}{l}1 \text { vision impairment, } \\
2 \text { scarring, } 3 \text { vessels }\end{array}$ \\
\hline 1) Minimal & $\begin{array}{l}\text { Mild haze, punctuate } \\
\text { epithelial erosions }\end{array}$ & None, none & Erythema, chemosis & None & Rapid & $1,2,3$ none \\
\hline 2) Mild & Opacified white & $\begin{array}{l}\text { None to minimal, } \\
\text { none }\end{array}$ & $\begin{array}{c}\text { Erythema, opacification, } \\
\text { chemosis }\end{array}$ & None & Rapid & $1,2,3$ none to little \\
\hline 3) Moderate & $\begin{array}{c}\text { Opacified white, common } \\
\text { at } 24-36 \text { hours }\end{array}$ & $\begin{array}{l}\text { Mild to moderate, } \\
\text { none }\end{array}$ & $\begin{array}{c}\text { Opacification, chemosis, } \\
\text { petechia or subconjunctival } \\
\text { haemorrhage }\end{array}$ & None to minimal & $\begin{array}{l}\text { Epithelial healing likely } \\
\text { within } 10 \text { days }\end{array}$ & $\begin{array}{l}1 \text { mild, } 2 \text { faint anterior scar } \\
\text { possible, } 3 \text { little tendency }\end{array}$ \\
\hline 4) Severe & $\begin{array}{c}\text { Entire epithelium opacified } \\
\text { white, usually large after } \\
24-36 \text { hours }\end{array}$ & $\begin{array}{c}\text { Moderate to } \\
\text { severe, mild } \\
\text { opacity obscures } \\
\text { iris details }\end{array}$ & $\begin{array}{c}\text { Opacification, } \\
\text { haemorrhages, necrosis }\end{array}$ & $<=1 / 3$ & $\begin{array}{l}\text { Epithelial healing possible } \\
\text { in weeks to months, } \\
\text { ulcers/ perforations }\end{array}$ & $\begin{array}{l}1 \text { moderate to severe, } 2 \text { moderate } \\
\text { anterior scar, } 3 \text { peripheral usual }\end{array}$ \\
\hline 5) Very severe & $\begin{array}{c}\text { Opacified white(if present) } \\
\text { and sloughs rapidly }\end{array}$ & Marked, severe & Necrosis may be extensive & $>1 / 3$ & $\begin{array}{l}\text { Protracted (months-yeas), } \\
\text { sloughing of stroma } \\
\text { possible with ulceration/ } \\
\text { perforation }\end{array}$ & $\begin{array}{c}1,2,3 \text { extensive, like severe alakali } \\
\text { injuries }\end{array}$ \\
\hline
\end{tabular}

Table 2: Classification of alkali burned eyes [21].

\begin{tabular}{|c|c|c|}
\hline Grade & Description & Prognosis \\
\hline Mild & $\begin{array}{c}\text { Corneal epithelial erosion, faint anterior stromal } \\
\text { haziness, no ischemic necrosis of perilimbal conjunctiva } \\
\text { and sclera. }\end{array}$ & $\begin{array}{l}\text { Healing with little or no corneal scarring; visual loss } \\
\text { usually no greater than one to two lines. }\end{array}$ \\
\hline Moderate & $\begin{array}{c}\text { Moderate corneal opacity, little or no significant ischemic } \\
\text { necrosis of perilimbal conjunctiva. }\end{array}$ & $\begin{array}{c}\text { Slow healing of epithelium with moderate scarring, } \\
\text { peripheral corneal vascularisation and visual loss of two } \\
\text { to seven lines. }\end{array}$ \\
\hline Moderate to severe & $\begin{array}{c}\text { Corneal opacity blurring iris details, ischemic necrosis } \\
\text { of conjunctiva limited to less than one-third of perilimbal } \\
\text { conjunctiva }\end{array}$ & $\begin{array}{l}\text { Prolonged corneal healing with significant corneal } \\
\text { vascularisation and scarring; vision usually limited to } \\
20 / 200 \text { or less. }\end{array}$ \\
\hline Severe & $\begin{array}{l}\text { Blurring of papillary outline, ischemia of approximately } \\
\text { one-third to two-third of perilimbal conjunctiva, cornea } \\
\text { often marbleized. }\end{array}$ & $\begin{array}{l}\text { Very prolonged corneal healing with inflammation and } \\
\text { high incidence of corneal ulceration and perforation. } \\
\text { In the best cases, severe corneal vascularisation and } \\
\text { scarring with counting fingers vision. }\end{array}$ \\
\hline Very severe & $\begin{array}{l}\text { Pupil not visible, greater than two-thirds ischemia of } \\
\text { perilimbal conjunctiva, cornea often marbleized. }\end{array}$ & $\begin{array}{l}\text { Very prolonged corneal healing with inflammation and } \\
\text { high incidence of corneal ulceration and perforation. } \\
\text { In the best cases, severe corneal vascularisation and } \\
\text { scarring with counting fingers vision. }\end{array}$ \\
\hline
\end{tabular}


- Topical steroids both low dose loteprednol $0.5 \%$ or fluromethalone $0.1 \%$ and prednisolone $1 \%$ eye drops were started on case to case basis.

- Both topical and oral NSAIDs were used where steroids were not used.

\section{8) Infective keratitis after injury with vegetative} matter

\section{Bacterial keratitis}

- After obtaining reports of gram staining and culture 4 cases of bacterial corneal ulcer were identified, 2 of them were Streptococcus pneumonia and 2 of them were Pseudomonas aeruginosa.

- All the 4 patients were started with fortified cefazolin eyedrops $50 \mathrm{mg} / \mathrm{ml}$ (5\%) and fortified tobramycin eyedrops $15 \mathrm{mg} / \mathrm{ml}(1.5 \%)$ hourly for the first 5 days followed by 4- 6 times for the next 9 days.

- Oral antibiotics in the combination of cefixime $200 \mathrm{mg}$ with ofloxacin $400 \mathrm{mg}$ was given for a week twice a day.

- Topical cycloplegic like atropine 1\% eye ointment was used bid for 5 days then switched over to topical $2 \%$ homatropine for the next 1 week.

- Anti-glaucoma medications like timolol maleate $0.5 \%$ eye drops and acetazolamide $250 \mathrm{mg}$ tablets were prescribed after tonometry and wherever required.

- Topical tear substitutes were used hourly.

- Supportive treatment like vitamin A capsules (5000 IU per day) and oral vitamin C 500mg tid was given.

- Oral analgesics to reduce pain.

- Surgical procedures were not required.

\section{Fungal keratitis}

- After obtaining the reports of positive $10 \% \mathrm{KOH}$ preparation, topical anti-fungal drugs like natamycin $5 \%$ eye suspension, fluconazole $0.3 \%$ eye drops were used hourly for the first 48 hours and then decreased to $2^{\text {nd }}$ hourly. Initially only natamycin suspension was used if the smear showed presence of septate hyphae and the response was noted. If the smear showed pseudo hyphae then fluconazole eye drops were also added. In the case not responding to natamycin alone, fluconazole eye drops were added. Topical therapy was continued at least $3^{\text {rd }}$ hourly for at least 2 weeks after healing of ulcer.

- After reports 2 cases of fungal corneal ulcer were identified out of which 1 was Fusarium solani and 1 was Aspergillus flavus.
- Topical cycloplegic like atropine $1 \%$ eye ointment was used bd for 5 days then switched over to topical $2 \%$ homatropine for the next 1 week.

- Anti-glaucoma medications like timolol maleate $0.5 \%$ eye drops and acetazolamide $250 \mathrm{mg}$ tablets were prescribed after tonometry and wherever required.

- Topical antibiotics eye drops like moxifloxacin $0.3 \%$ was used hourly.

- Topical tear substitutes were used hourly.

- Supportive treatment like vitamin A capsules (5000 IU per day) and oral vitamin C 500mg tid was given.

- Oral analgesics to reduce pain.

- Oral anti-fungal was used in corneal ulcer with deep stromal involvement in the form of fluconazole $200 \mathrm{mg}$ twice a day for 15 days. Liver function tests were done before initiating the therapy.

- Surgical debridement of ulcer was performed for 1 case under topical anesthesia on a slit lamp with a Bard Parker blade No.15. This was done daily to help penetration of drugs until the ulcer showed decrease in infiltration.

\section{9) Corneal perforation}

- After diagnosing perforating injury, the patient was started on systemic antibiotics (cefixime with ofloxacin combination) and Tetanus toxoid prophylaxis was given.

- X-ray orbit was taken and the medico legal aspects were settled.

- A B-scan was done to see for the posterior segment involvement.

- In our study 2 cases of corneal perforation with incarceration of iris was noted immediately after the injury.

- Under peribulbar anesthesia with $2 \%$ lignocaine with adrenaline the iris tissue in the wound was removed with suturing of the iridodialysis performed through the wound. The iris lens diaphragm was maintained without any posterior segment disturbances. The side port entry was made and thorough anterior chamber wash was given.

- Throughout the procedure anterior chamber was maintained with viscoelastic substance.

- The corneal laceration was closed with 10-0 ethylon interrupted sutures and the knots were buried in the stroma away from the visual axis and trimmed.

- Intracameral $0.4 \mathrm{ml}$ of moxifloxacin was given to prevent endophthalmitis. 
- After wound closure the anterior chamber was formed and excessive viscoelastic was washed away. Care was taken to note any wound gaping.

- The patient was continued on oral antibiotics and analgesics for a week.

- Post operatively patient was started on topical antibiotics (moxifloxacin $0.5 \%$ ) hourly, tear substitute hourly, topical prednisolone $1 \%$ hourly, topical flurbiprofen $0.3 \%$ qid, cycloplegic ( $2 \%$ homatropine) bid and antiglaucoma medication was given after tonometry.

- On every visit wound leak was checked by performing a seidel's test.

- Steroids, antibiotics and cycloplegics were tapered over a period of 2 months.

- Sutures were removed after 3 months after noting wound fibrosis under topical anesthetics (proparacaine eye drops) and topical antibiotics was continued for a week and stopped.

The patients were examined on days 1, 2, 3 followed by first week second week, fourth week, $2^{\text {nd }}$ month and $4^{\text {th }}$ month depending upon the type of injury and the healing rate. At each follow up the wound details including fluorescein staining and visual acuity was recorded. At the end of $4^{\text {th }}$ month the type of corneal opacity if developed was noted with the visual acuity recorded.

\section{Results}

- The study showed that majority of the patients were in the age groups from 21-65 years. It was less in the younger age groups and the least amongst older individuals.

- $69 \%$ patients were male and $31 \%$ were female.

- $30 \%$ patients suffered corneal abrasion injuries, $27 \%$ suffered corneal foreign body injuries, $21 \%$ chemical injuries, $9 \%$ radiation trauma, $6 \%$ blunt injuries, 5\% sting injuries and $2 \%$ lacerating injuries (Graph 1 ).

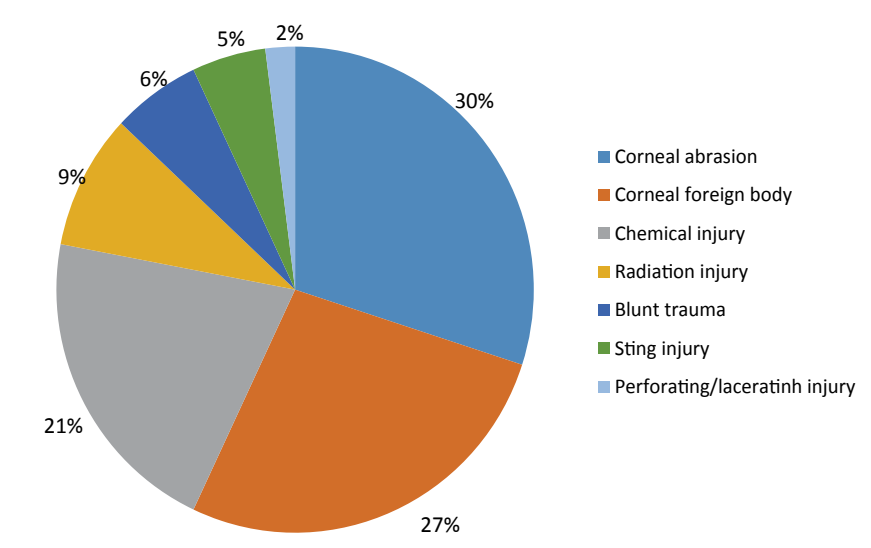

Graph 1: Showing types of injury sustained.
- Alkali injuries were more common (61.9\%) than acid injuries (38.1\%).

- $94 \%$ presented within the first 24 hours, $4 \%$ within 24-48 hours and $2 \%$ after 48 hours after sustaining injuries.

- $65 \%$ patients had only epithelial injuries, $21 \%$ had injuries extending till the anterior stroma, $12 \%$ injuries reaching mid stroma and Descemet's membrane and only $2 \%$ patients had perforating corneal injuries.

- $65 \%$ patients had the pupillary area of cornea involved while $35 \%$ had the pupillary area spared.

- $93 \%$ patients had noninfectious injuries at the time of presentation, $4 \%$ had bacterial infection of the wound while $3 \%$ had fungal infections.

- $97 \%$ were given conservative management while only $3 \%$ were given surgical management.

- After treatment, $81 \%$ showed clear cornea, $9 \%$ had nebular grade opacities, 7\% macular grade opacities and 3\% had leucomatous opacities (Graph 2).

- The visual outcome showed $83 \%$ cases with normal vision, $14 \%$ had low vision and $3 \%$ had blindness.

- The visual outcome of patients with corneal injuries encroaching pupillary area showed $75 \%$ patients with normal vision, $20.6 \%$ with low vision and $4.4 \%$ patients with blindness.

- The visual acuity at presentation showed $8 \%$ cases with perception of light, projection of rays and finger counting at 3 meters. $62 \%$ with vision $6 / 18$ or worse and $30 \%$ with visual acuity better than $6 / 18$ (Graphs 3,4 ) shows the visual outcome at the fourth month after
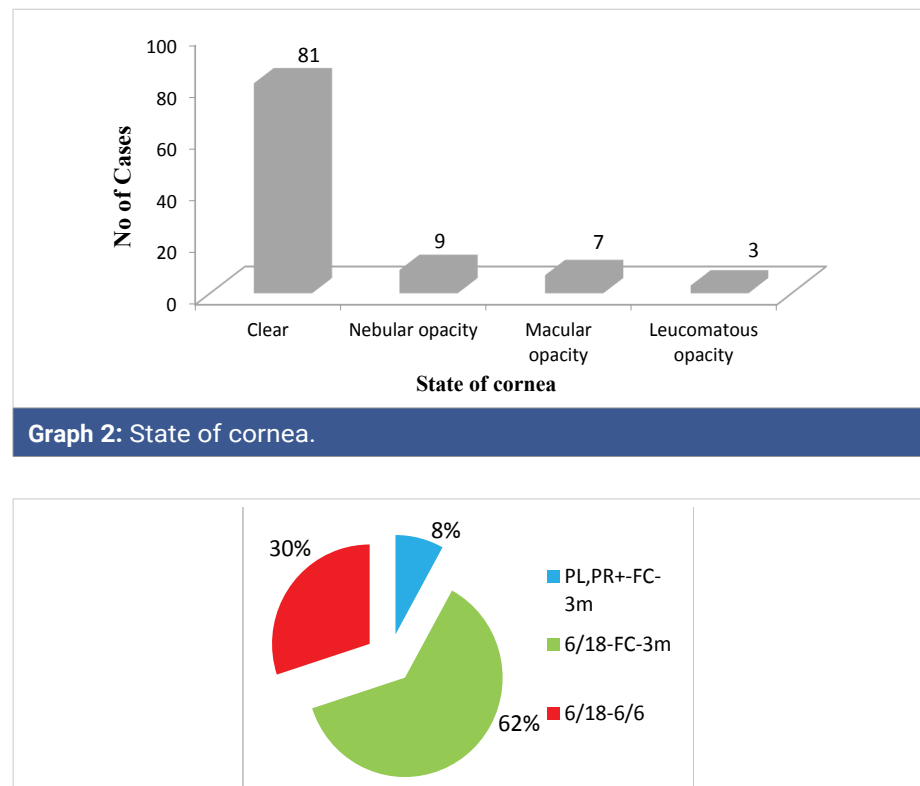

Graph 3: Visual acuity at presentation. 
presentation with the injury (Table 3).

- Table 3 shows the visual outcome in various types of corneal injuries (Graph 5).

- Table 4 shows the depth of the defect and the corneal opacity developed (Graph 6).

- Table 5 shows the depth of corneal defect and visual outcome (Graph 7).

- Table 6 shows corneal opacity due to corneal injuries and their visual outcome (Graph 8).

- Table 7 shows the relation between depth of defect and healing of defect (Graph 9).

- Table 8 shows the percentage of benefit obtained in vision before and after treatment in different studies.

- Table 9 shows the comparison of visual outcome in different studies.

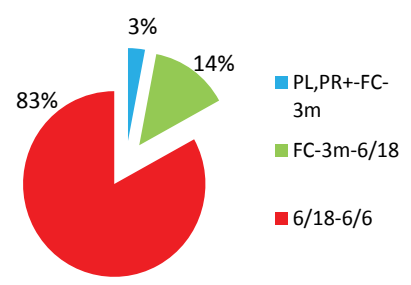

\section{Graph 4: Visual acuity at $4^{\text {th }}$ month.}

Table 3: Visual outcome in various types of corneal injuries.

\begin{tabular}{|c|c|c|c|c|}
\hline Type of injury & $\begin{array}{c}\text { Normal } \\
\text { vision(6/6-6/18) } \\
\text { and percentage }\end{array}$ & $\begin{array}{c}\text { Low vision (6/18- } \\
\text { FC 3metre) and } \\
\text { percentage }\end{array}$ & $\begin{array}{c}\text { Blindness(FC 3 } \\
\text { metre- no PL/PR) } \\
\text { and percentage }\end{array}$ & Total \\
\hline $\begin{array}{c}\text { Corneal } \\
\text { abrasion }\end{array}$ & $25(83.3 \%)$ & $4(13.3 \%)$ & $1(3.4 \%)$ & 30 \\
\hline $\begin{array}{c}\text { Corneal Foreign } \\
\text { body }\end{array}$ & $19(70.4 \%)$ & $8(29.6 \%)$ & $0(0 \%)$ & 27 \\
\hline Blunt trauma & $6(100 \%)$ & $0(0 \%)$ & $0(0 \%)$ & 6 \\
\hline $\begin{array}{c}\text { Perforating / } \\
\text { lacerating injury }\end{array}$ & $0(0 \%)$ & $0(0 \%)$ & $2(100 \%)$ & 2 \\
\hline Chemical injury & $19(90.5 \%)$ & $2(9.5 \%)$ & $0(0 \%)$ & 21 \\
\hline Sting injury & $5(100 \%)$ & $0(0 \%)$ & $0(0 \%)$ & 5 \\
\hline Radiation injury & $9(100 \%)$ & $0(0 \%)$ & $0(0 \%)$ & 9 \\
\hline Total & 83 & 14 & 3 & 100 \\
\hline
\end{tabular}

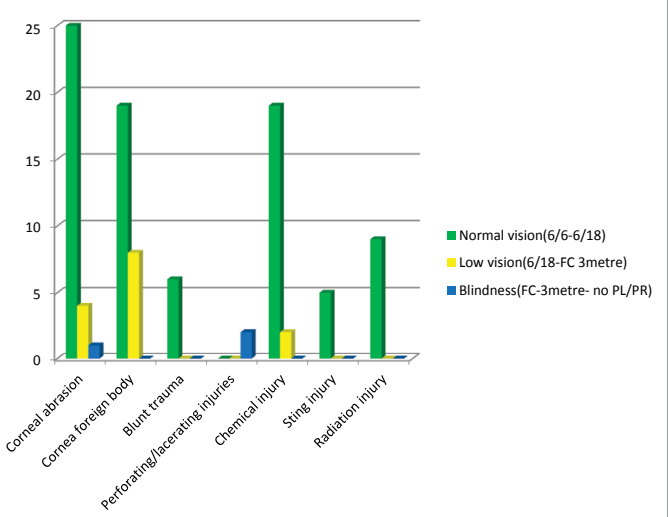

Figure 5: Showing visualout comein various forms of corneal injuries.

\begin{tabular}{|c|c|c|c|c|c|}
\hline & $\begin{array}{c}\text { Clear } \\
\text { cornea and } \\
\text { percentage }\end{array}$ & $\begin{array}{c}\text { Nebular } \\
\text { opacity and } \\
\text { percentage }\end{array}$ & $\begin{array}{c}\text { Macular } \\
\text { opacity and } \\
\text { percentage }\end{array}$ & $\begin{array}{c}\text { Leucomatous } \\
\text { opacity and } \\
\text { percentage }\end{array}$ & Total \\
\hline Epithelium & $65(100 \%)$ & $0(0 \%)$ & $0(0 \%)$ & $0(0 \%)$ & 65 \\
\hline $\begin{array}{l}\text { Anterior } \\
\text { stroma }\end{array}$ & $11(52.3 \%)$ & $9(42.9 \%)$ & $1(4.8 \%)$ & $0(0 \%)$ & 21 \\
\hline Mid stroma & $5(41.7 \%)$ & $0(0 \%)$ & $6(50 \%)$ & $1(8.3 \%)$ & 12 \\
\hline $\begin{array}{c}\text { Full } \\
\text { thickness }\end{array}$ & $0(0 \%)$ & $0(0 \%)$ & $0(0 \%)$ & $2(100 \%)$ & 2 \\
\hline Total & 81 & 9 & 7 & 3 & 100 \\
\hline
\end{tabular}

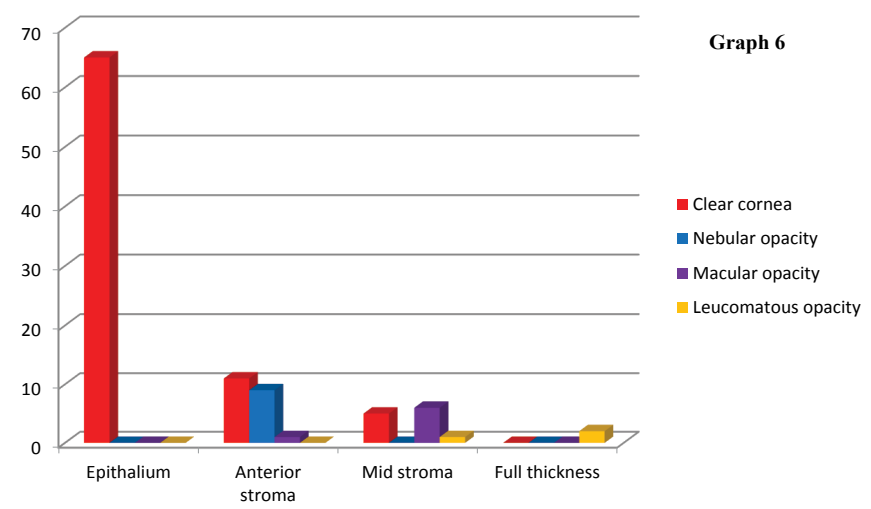

Figure 6: Shows the depth of the defect and the corneal opacity developed.

Table 5: Showing depth of corneal defect and the visual outcome (Graph 7).

\begin{tabular}{|c|c|c|c|c|}
\hline & $\begin{array}{c}\text { Normal vision } \\
(6 / 6-6 / 18) \text { and } \\
\text { percentage }\end{array}$ & $\begin{array}{c}\text { Low vision (6/18- } \\
\text { FC 3metre) and } \\
\text { percentage }\end{array}$ & $\begin{array}{c}\text { Blindness (FC 3 } \\
\text { metre- no PL/PR) } \\
\text { and percentage }\end{array}$ & Total \\
\hline Epithelium & $65(100 \%)$ & $0(0 \%)$ & $0(0 \%)$ & 65 \\
\hline $\begin{array}{c}\text { Anterior } \\
\text { stroma }\end{array}$ & $13(61.9 \%)$ & $8(38.1 \%)$ & $0(0 \%)$ & 21 \\
\hline Mid stroma & $5(41.7 \%)$ & $6(50 \%)$ & $1(8.3 \%)$ & 12 \\
\hline Full thickness & $0(0 \%)$ & $0(0 \%)$ & $2(0 \%)$ & 2 \\
\hline Total & 83 & 14 & 2 & 100 \\
\hline
\end{tabular}

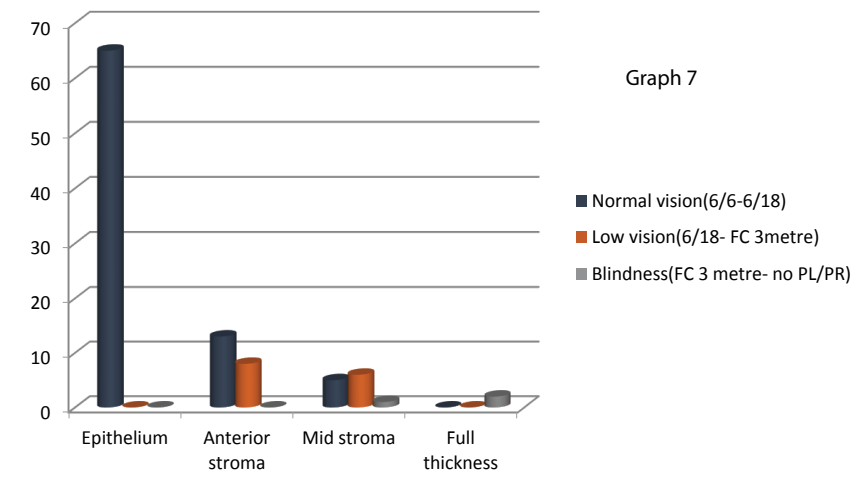

Figure 7: Shows the depth of corneal defect and visual outcome.

Table 6: Showing corneal opacity due to corneal injuries and their visual outcome (Graph 8)

\begin{tabular}{|c|c|c|c|c|c|}
\hline & $\begin{array}{c}\text { Clear } \\
\text { cornea }\end{array}$ & $\begin{array}{c}\text { Nebular } \\
\text { opacity }\end{array}$ & $\begin{array}{c}\text { Macular } \\
\text { opacity }\end{array}$ & $\begin{array}{c}\text { Leucomatous } \\
\text { opacity }\end{array}$ & Total \\
\hline $\begin{array}{c}\text { Normal vision (6/6-6/18) } \\
\text { and percentage }\end{array}$ & $81(97.6 \%)$ & $1(1.2 \%)$ & $1(1.2 \%)$ & $0(0 \%)$ & 83 \\
\hline $\begin{array}{c}\text { Low vision (6/18 - FC } \\
\text { 3metre) and percentage }\end{array}$ & $0(0 \%)$ & $8(57.1 \%)$ & $6(42.9 \%)$ & $0(0 \%)$ & 14 \\
\hline $\begin{array}{c}\text { Blindness (FC 3 metre - no } \\
\text { PL/PR) and percentage }\end{array}$ & $0(0 \%)$ & $0(0 \%)$ & $0(0 \%)$ & $3(100 \%)$ & 3 \\
\hline Total & 81 & 9 & 7 & 3 & 100 \\
\hline
\end{tabular}




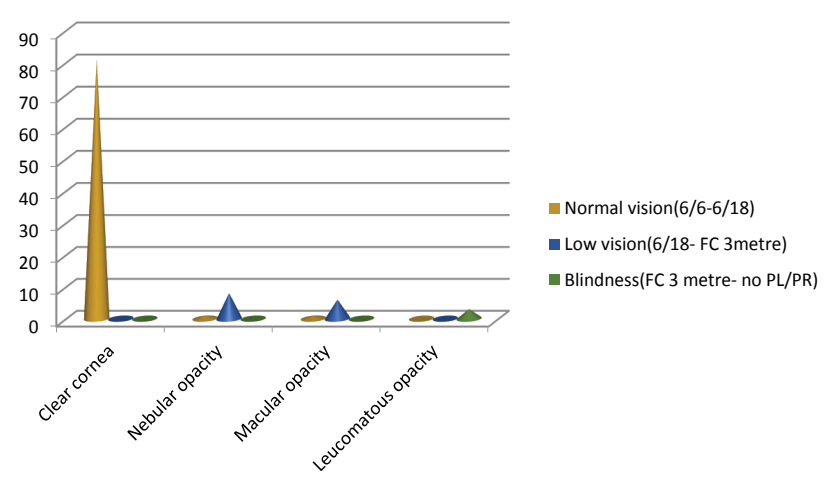

Figure 8: Shows corneal opacity due to corneal injuries and their visual outcome.

Table 7: Showing relation between Depth of defect and healing of defect.

\begin{tabular}{|c|c|c|c|c|}
\hline Depth of Defect & No. of Cases & $\begin{array}{c}\text { Healed with normal } \\
\text { vision } \mathbf{n}(\%)\end{array}$ & \multirow{2}{*}{$\mathbf{X}^{2}$} & P value \\
\hline Epithelium & 65 & $65(100 \%)$ & & \multirow{2}{*}{$0.01 \mathrm{~S}$} \\
\hline Anterior stroma & 21 & $13(61.9 \%)$ & & \\
\hline Mid stroma & 12 & $5(41.7 \%)$ & & \\
\hline Full thickness & 2 & $0(0 \%)$ & & \\
\hline
\end{tabular}

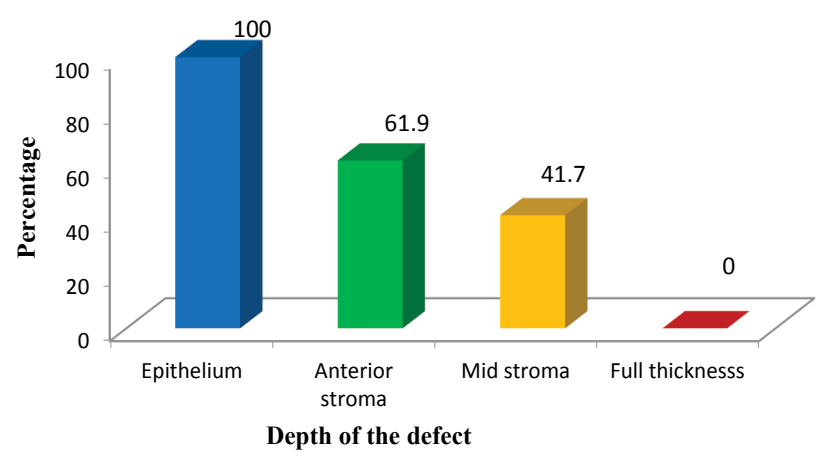

Figure 9: Showing relation between Depth of defect and healing of defect.

Table 8: Percentage of benefit obtained in vision before and after treatment in different studies.

\begin{tabular}{|c|c|c|}
\hline WHO Categories & Adhikari RK study [9] & Present study \\
\hline Normal vision(6/6-6/18) & $41.74 \%$ & $53 \%$ \\
\hline Low vision (6/18- FC 3metre) & $21.7 \%$ & $48 \%$ \\
\hline Blindness (FC 3 metre- no PL/PR) & $10.56 \%$ & $5 \%$ \\
\hline
\end{tabular}

Table 9: Comparison of visual outcome of different studies.

\begin{tabular}{|c|c|c|c|}
\hline WHO Categories & Caroline study [20] & Adhikari RK study [9] & Present study \\
\hline $\begin{array}{c}\text { Normal vision (6/6-6/18) } \\
\text { Low vision (6/18- FC 3 } \\
\text { metre) }\end{array}$ & $75 \%$ & $54.24 \%$ & $83 \%$ \\
\hline $\begin{array}{c}\text { Blindness (FC 3 metre- } \\
\text { no PL/PR) }\end{array}$ & $15 \%$ & $24.4 \%$ & $14 \%$ \\
\hline
\end{tabular}

In this study, $100 \%$ of the patients with epithelium injury gained normal visual acuity, as the depth of defect increased the visual acuity decreased with low visual outcome, $61.9 \%$ of patients with anterior stromal defects gained normal visual acuity while $41.7 \%$ of patients with mid stromal defects gained normal visual acuity but none of the patients with full thickness corneal injuries could get normal visual acuity and this was statistically significant as the $p$ value was 0.01 using Chi square test.

\section{Discussion}

Amongst the 100 cases of corneal injuries study the most common age group affected was between 21 and 40 years followed by $<20$ years, $41-65$ years and $>65$ yrs. According to R.K. Adhikari's study, injuries were more in most active period of life (15-50) years and there were 15\% lesions among children and lesions declined after the age of 71 . This has a considerable socioeconomic impact because people of this age group are bread winners of their families [1]. This coincides with Rapti's study also [10].

In terms of gender of the patients, males were more affected than females. In other similar studies males were exposed in outdoor activity and they were preferred for early treatment, so the study showed more lesions in male (59\%) than female $(41 \%)[9,10]$.

Regarding the types of injuries, corneal abrasions were the cause of $10 \%$ of new patient visits to the ophthalmic emergency room in an English series [11]. In a study of corneal abrasions in Bhaktapur (Nepal) evaluating sequential corneal ulceration, the annual incidence of corneal abrasions was estimated at 789/100,000 [3].

Second to corneal abrasions, corneal foreign bodies were the most common form of ophthalmic trauma. In a recent study in northern Sweden, the incidence of eye injuries was estimated to be 8.1 per 1000 population, with corneal foreign bodies comprising $40 \%$ of these [12].

Banerjee, in a similar study, found that of 25,000 new patients seen in an emergency room in England over a 6-month period, $472(1.8 \%)$ were patients who had ocular foreign bodies that occurred at work. Most of the patients had foreign body injury at work places like grinding factory, iron factory and other factories surrounding our hospital [13].

In another German study of 101 patients with 131 severely burned eyes, $72.3 \%$ of the injuries were work-related, $84.2 \%$ were chemical injuries, and $79.8 \%$ of these were due to alkalis which was in agreement with the present study [14]. According to a similar study by Kuckelkorn, et al. most of the chemical injuries were classified as mild which is also consistent with our present study [15-17].

According to Subrata Das, et al. [15] study majority of the cases were alkali injuries as lime is the common chemical substance with majority $48 \%$ as minimal to mild grade injury.

A total of $74.1 \%$ of the foreign body injuries were caused by sterile foreign bodies and $25.9 \%$ were vegetative. In a similar study by Dandona, et al. [5] studies $27.3 \%$ were with vegetative matter and others were sterile and chemicals which are similar to our study.

Our study explains that early reported cases had good results which was proved by Adhikari, study also [9]. 
Both Adhikary, and Caroline's studies proved that medical and conservative management was sufficient for superficial and non-infective conditions $[9,10]$.

Moreover, the significance of involvement of the pupillary area was seen in our study.

Out of the 100 cases studies $94 \%$ were non-infectious and $6 \%$ were infectious with 4 bacterial infections ( 2 with Streptococcus pneumonia and 2 with Pseudomonas aeruginosa) and 2 fungal infections (1 fusarium and 1 Aspergillus Flavus). Out of the 6 cases 4 cases had low vision, 1 had normal vision and 1 had blindness.

Our study showed that there were 30 cases of corneal abrasions out of which $25(83.3 \%)$ had normal vision at the end, $4(13.3 \%)$ had low vision and $1(3.4 \%)$ had blindness. The low vision was due to formation of nebular opacity in 2 cases with history of trauma with finger nail and pencil. In other 2 cases there was macular opacity, one had developed bacterial corneal ulcer (Pseudomonas) due to cat scratch injury and other had injury with animal tail which developed fungal corneal ulcer (Aspergillus flavus) both of them were presented to us after 24 hours of the injury. The fungal ulcer patient underwent surgical debridement, others were managed conservatively. Out of 27 cases of corneal foreign body injury $19(70.4 \%)$ were restored with normal vision, $8(29.6 \%)$ had low vision due to development of nebular opacity in 6 cases at the pupillary area and macular opacity in 2 cases due to formation of bacterial corneal ulcer due to Pseudomonas and Streptococcus, none $(0 \%)$ ended up in blindness. Out of 21 cases of chemical injury to the cornea, $19(90.5 \%)$ of the patients had normal vision with minimal to mild severity of injury, 2(9.5\%) cases had low vision due to development of macular opacity with moderate severity of injury and none $(0 \%)$ had blindness. According to Subrata Das, et al. study $76 \%$ patients had normal vision at the end of the study with $18 \%$ low vision and $6 \%$ blindness [18]. Out of 9 cases of radiation injury all $(100 \%)$ had normal vision. All of the 6 cases of blunt trauma and 5 cases of honey bee sting injuries all $(100 \%)$ had normal vision at the end of the study. Out of 2 perforating/lacerating injury both $(100 \%)$ had blindness due to development of leucomatous opacity. SK Khatry, et al. had similar findings regarding penetrating injuries of cornea [19].

Our study also showed that full thickness injuries have a devastating outcome like the SK Khatry's studies [19].

The study also tells us the importance of depth of corneal injuries in the visual outcome. The test of significance of depth of defect with corneal wound healing and the visual outcome was proved by the chi square test with a p value of 0.01 .

\section{Conclusion}

Corneal injuries continue to be an important cause of corneal morbidity. The various demographic factors like age, sex and patterns of corneal injuries were studied and it was found that most of the corneal injuries were seen in working (21-40 yrs) and the daily bread earning male population of the society $[20]$.

Most of the corneal injuries (30\%) were abrasion injuries followed by sterile foreign body injuries (27\%) occurring in the industrial premises. The third leading injury (21\%) was chemical injury by alkali as lime is the most common agent used in daily occupational work [21].

Most (94\%) of the patients reported within 24 hours of injury hence early treatment was given and visual outcome was good in these cases. This necessitates the importance of early treatment after corneal injury.

Corneal injuries affecting the pupillary area of the cornea posed a greater threat to the final visual outcome as opposed to the paracentral and peripheral corneal involvement.

Most of the corneal injuries (65\%) involved only the epithelial layer of cornea so most of them required only conservative management. The majority of the corneal injuries (81\%) had clear cornea and normal vision (6/6-6/18) as visual outcome at the end of our study.

Corneal injuries involving the epithelium and anterior stroma had very good prognosis in terms of visual outcome. Those involving the mid stroma and full thickness corneal lacerations had poor prognosis having only low vision 6/18$\mathrm{FC} 3 \mathrm{~m}$ ) and blindness (CF $3 \mathrm{~m}-\mathrm{no} \mathrm{PL} / \mathrm{PR}$ ) as the visual outcome according to $\mathrm{WHO}$ criteria.

Most important causes of blindness in our study was full thickness corneal laceration followed by infectious keratitis presenting after 24 hours of injury and involving mid stroma causing leucomatous opacity. Most important causes of low vision in our study was corneal abrasions and corneal foreign body injury affecting the pupillary area and involving anterior or mid stroma causing nebular or macular grade of opacity hampering the vision.

In most of the cases of corneal injuries are preventable. It appears that early treatment can restore good vision and use of eye protective glass while working will be the preventive measure, and use of antibiotics drops after injury will be the proper method of treatment.

\section{Acknowledgements}

Dr. Aarudhra Premchander, Dr. Seema Channabasappa and Dr. Nischala Balakrishna for collecting the case data and details and compilation. Dr. Neha Nargis for help with language and proof reading the article.

This research did not receive any specific grant from funding agencies in the public, commercial or non-profit sectors. 


\section{Method of literature search}

Identifying search terms and synonyms for the keywords of the standard reference articles used, preferably from the past 5 years. Synonyms of the specific keywords were also searched for and relevant literature generated through exploring Google Scholar and PubMed and a pool of offline material. Due to the word limit imposed, literature was filtered according to credentials of authors and filtered according to contribution of the text to development of the research area.

\section{References}

1. Krachmer, Mannis and Holland: Book of Cornea; Second Edition 2005:Volume1; Section 8-Corneal Trauma; Chapter 100: Mechanical Injury. 1245.

2. Thylefors B, Negrel Ad, Pararajasegaram R, Dadzie Ky. Global data on blindness. Bull Who.1995; 72:115.

PubMed: https://www.ncbi.nlm.nih.gov/pubmed/7704921

3. Upadhyay MP, Karmacharya PC, Koirala S, Shah DN, Shakya S, et al. The bhaktapur eye study: ocular trauma and antibiotic prophylaxis for the prevention of corneal ulceration in Nepal. Br J Ophthalmol. 2001; 85: 388-392.

PubMed: https://www.ncbi.nlm.nih.gov/pmc/articles/PMC1723912/

4. Rao GN. Corneal opacification in the developing world Chapter 61 .

5. Dandona R, Dandona L. Corneal blindness in a southern indian population: need for health promotion strategies. $\mathrm{Br} \mathrm{J}$ Ophthalmol. 2003; 87: 133-141.

6. Sinha R, Sharma N, Rasik B. Vajpayee. Corneal blindness present status. Tackling World Blindness. 2005; 61.

7. Krachmer, Mannis and Holland: Book of Cornea; Second Edition 2005: Volume 1; Section 8-Corneal Trauma; Chapter 100: Mechanical Injury: $\operatorname{Pg} 1246$.

8. Krachmer, Mannis and Holland: Book of Cornea; Second Edition 2005 Volume 1; Section 8-Corneal Trauma; Chapter 100: Mechanical Injury. 1256.

9. Adhikari RK. Analysis of corneal injuries in king mahendra memorial eye hospital Bharatpur, Chitwan. Kathmandu Univ Med J (KUMJ). 2006; 4: 34-39.

PubMed: https://www.ncbi.nlm.nih.gov/pubmed/18603865
10. Macewen CJ. Glasgow eye infirmary, eye injuries a prospective survey of 5671 cases. $\mathrm{Br} \mathrm{J}$ Ophthalmol. 1989; 73: 888-894.

PubMed: https://www.ncbi.nlm.nih.gov/pubmed/2605143

11. Chiapella AP, Rosenthal AR. One year in an eye casualty. $\mathrm{Br} J$ Ophthalmol. 1985; 69: 865-870.

PubMed: https://www.ncbi.nlm.nih.gov/pubmed/4063253

12. Monestam E, Bjornstig. Eye injuries in northern sweden. Acta Ophthalmol. 1991; 69: 1-5.

13. Banerjee A. Effectiveness of eye protection in the metal working industry. BMJ. 1990; 301: 645-646. PubMed: https://www.ncbi.nlm.nih.gov/pmc/articles/PMC1663866/

14. Kuckelkorn R, Kottek A, Schrage N, Reim M. Poor prognosis of severe chemical and thermal eye burns: the need for adequate emergency care and primary prevention. Int Arch Occup Environ Health.1995; 67 281-284.

PubMed: https://www.ncbi.nlm.nih.gov/pubmed/7591189

15. Benjamin DA, Qian Garrett, Mark W. Corneal injuries and wound healing -review of processes and therapie. Austin Journal of Clinical Ophthalmology. 2014; 1: 1-25.

16. Kuckelkorn R, Luft I, Kottek AA, Schrage NF, Makropoulos W, et al Chemical and thermal eye burns in the residential area of rwth aachen. Analysis of accident in 1 year using a new automated documentation of findings. Klin Monbl Augenheilkd. 1993; 203: 34-42. PubMed: https://www.ncbi.nlm.nih.gov/pubmed/8411890

17. Kuckelkorn M, Makropoulos W, Kotteck A, Reim M. Retrospective study of severe alkali burns of the eyes. Klin Monatsbl Augenheikd. 1993; 203: 397-402.

PubMed: https://www.ncbi.nlm.nih.gov/pubmed/8145483

18. Das S, Kabir MF, Das J. Pattern of chemical ocularinjury: a clinica study, Chattagram Maa-O-Shishu Hospital Medical College. Journal. 2014; 13: 42-45

19. McCulley JP. Ocular hydrofluoric acid burns: animal model, mechanism of injury and therapy. Transam Ophthalmol Soc. 1990; 88: 649-684. PubMed: https://www.ncbi.nlm.nih.gov/pmc/articles/PMC1298602/

20. Whitcher JP, Srinivasan M, Upadhyay MP. Corneal blindness: a global perspective. Bull World Health Organ. 2001; 79: 214-221. PubMed: https://www.ncbi.nlm.nih.gov/pubmed/11285665

21. Pfister RR, Koski J. The pathophysiology and treatment of the alkaliburned eye. South Med J. 1982; 75: 417-422.

22. Friedenwald JS, Hughes WF, Hermann H. Acid-base tolerance of thecornea. Arch Ophthalmol. 1944; 31: 279-283. 